\section{Articulação entre saberes: etnografia da atenção à saúde no contexto guarani mbya de Paraty $R \mathrm{~J}$ The articulation of knowledge: the ethnography of attention given to health in the context of the Guarani Mbya in Paraty - Rio de Janeiro}

\author{
Donizete Vago Daher* \\ Lalita Paiva Santos** \\ Vicente Cretton Pereira ${ }^{* * *}$
}

Resumo O presente artigo é resultado de uma pesquisa realizada entre 2008 e 2009, em três aldeias de etnia Guarani Mbya, no município de ParatyRJ e tem como objetivo descrever e situar alguns aspectos da articulação entre o saber indígena em saúde e o saber biomédico da equipe multidisciplinar de saúde indígena, no contexto indicado, ressaltando a questão da Atenção Diferenciada. Questão esta definida pelo Subsistema de Saúde Indígena como: ações em saúde realizadas com respeito às diferenças socioeconômicas, epidemiológicas, demográficas e culturais de cada comunidade indígena. Contudo, percebemos que as equipes de saúde ainda encontram dificuldades em relação à elaboração de um atendimento que englobe a concepção de saúde dos Guarani Mbya e os seus modos de cuidado.

Palavras-chave: Saúde Indígena; Índios Guarani; Enfermagem.

Abstract: The present article is a result of research carried out between the years of 2008 and 2009 in three villages of the Guarani Mbya ethnic group, in Paraty-RJ and has as its objective, describing and situating some aspects of the articulation between indigenous health knowledge and the biomedical knowledge of the multidisciplinary team for indigenous health, in the aforementioned context, emphasizing the question of Differentiated Attention. This is defined by the Subsystem of Indigenous Health as: health actions carried out in different indigenous communities with socioeconomic, demographic, and cultural differences. Notwithstanding, it was perceived that the health teams still have difficulties in elaborating a service which involves the Guarani Mbya conception of health and their own ways of caring.

Key-words: Indigenous Health; Health Systems; Guarani Indians
* Doutora em Saúde Coletiva pela Universidade Estadual de Campinas UNICAMP. Professora da Universidade Federal Fluminense. Apoio

financeiro do Conselho Nacional de Desenvolvimento Científico e Tecnológico (CNPq) para a realização da pesquisa, entre 2008 e 2010. E-mail: donizete@predialnet.com.br.

** Enfermeira licenciada pela Universidade Federal

Fluminense. E-mail: lalitagopi12@yahoo.com.br.

*** Mestre em Ciências

Sociais pela Universidade do Estado do Rio de Janeiro. E-mail: vcretton@bol.com.br. 


\section{Primeiros momentos entre os Guarani: definindo a pesquisa}

Nosso primeiro contato com os Guarani Mbya do estado do Rio de Janeiro se deu no ano de 2007, por conta de uma viagem ao Saco do Mamanguá, estuário marinho localizado ao sul de Paraty, próximo à praia de Paraty Mirim. A partir deste contato inicial com os Guarani Mbya e de estudos anteriores sobre a temática saúde indígena, nos sentimos encorajados a submeter um projeto para o edital "Seleção de propostas avaliativas do Subsistema de Saúde Indígena" promovido pelo MS/FUNASA-MS/ SCTIE/DECIT-OPAS/2007. Na construção da proposta, que foi então aprovada, nosso objetivo inicial era investigar a implantação do subsistema de saúde indígena tal como acontecia na aldeia Arandu Mirim, localizada no Saco do Mamanguá.

A exclusividade desta aldeia em nossa pesquisa não pôde se manter após o início do trabalho de campo por duas razões principais: a primeira delas diz respeito a uma dinâmica inerente aos moradores da aldeia do Mamanguá, os quais necessitam, por razões específicas, realizar um deslocamento quase que constante até a aldeia de Paraty Mirim. Este fato se dá porque a aldeia Arandu Mirim não possui posto de saúde, tampouco agente indígena de saúde (AIS), de modo que os atendimentos são realizados em sua maioria no posto da aldeia de Paraty Mirim (ainda que a equipe de saúde visite o Mamanguá com alguma frequência). A segunda razão para nossa impossibilidade de manter o Mamanguá como horizonte exclusivo de pesquisa teve a ver com nossa aprovação mediante o Conselho Local de Saúde dos Guarani do Rio de Janeiro, no qual estavam presentes representantes de todas as aldeias da região.

Antes de nossa entrada em campo apresentamos nossa proposta durante uma reunião do Conselho realizada no Polo Base de Angra dos Reis, localizado no bairro do Perequê. Nesse evento estavam presentes a coordenadora da saúde indígena do estado do Rio de Janeiro e também vários Guarani, inclusive algumas lideranças importantes. Na ocasião, observamos o transcorrer ordinário deste tipo de reunião: primeiro os Guarani fazem uma discussão (na língua guarani mbya, o que impedia a compreensão da maioria dos não-índios que estavam presentes) entre eles e só depois chamam os jurua (não-índios) para passarem o que foi discutido. Por final, conseguimos nos apresentar e explicar os nossos objetivos e maneiras de trabalho, reafirmando que, antes de remetermos o projeto ao Conselho Nacional de Desenvolvimento Científico e Tecnológico (CNPq), já tínhamos consultado o cacique da aldeia Mamanguá, 
o qual confirmou pessoalmente sua aprovação. Após breve discussão, realizada na língua mbya guarani entre as principais lideranças então presentes, houve a reivindicação de que a pesquisa fosse estendida às demais aldeias da região. Como disse o cacique de Araponga, especialmente por se tratar de um projeto na área da saúde, não poderia ficar restrito a uma só aldeia.

Diante deste quadro reavaliamos as nossas possibilidades levando em conta que os Guarani do Mamanguá estão em constante relação com a aldeia de Paraty Mirim e, além disso, praticamente a mesma equipe médica atende nas duas localidades. Consideramos, portanto, a reivindicação do cacique da aldeia de Araponga deveras justificada e decidimos, desta forma, ampliar o âmbito de nossa pesquisa que abrangia, além da aldeia do Mamanguá, a de Paraty Mirim e a de Araponga. A primeira porque seria inevitável, já que os moradores do Mamanguá também são atendidos no posto de saúde dali, e a segunda, por ser a mais próxima das outras duas, e nos poupar excessivo dispêndio de recursos e de tempo em deslocamentos rodoviários (os quais haviam sido planejados a fim de atender uma pesquisa em uma única aldeia). Atendidas pelo Polo Base de Angra dos Reis existem ainda as aldeias de Bracuí e de Rio Pequeno, as quais ficaram de fora do âmbito de nossa pesquisa.

Desta forma, nosso objetivo principal é, a partir do trabalho de campo nas aldeias de Paraty Mirim, Mamanguá e Araponga descrever e situar a articulação entre o saber guarani em saúde e o saber biomédico da equipe multidisciplinar de saúde indígena (EMSI), buscando ressaltar a questão da atenção diferenciada, uma das diretrizes da Política Nacional de Atenção à Saúde dos Povos Indígenas instituída pelo Subsistema de Saúde Indígena (criado em 1999, pela Lei n. 9.836). Estudos recentes, como o de Pellegrini (2004, p.237), apontam que este mesmo conceito necessita ser operacionalizado em certos níveis do SUS, já que os profissionais de saúde não são/estão capacitados para trabalhar com as especificidades de determinadas culturas, como as indígenas.

\section{Os contextos da pesquisa: as aldeias de Mamanguá, Paraty Mirim e Araponga}

Faz-se necessária, portanto, uma breve descrição dos cenários nos quais a pesquisa se desenrolou, destacando algumas de suas especificidades. Como afirmam Ladeira (2008) e Ciccarone (2004), as ocupações guarani mbya no estado do Rio de Janeiro remontam ao caminhar 
(-guata) de uma importante liderança espiritual: Dona Maria Tataxi Yvy Rete, a qual iniciou sua jornada no Paraguay. D.Maria e seu grupo familiar demarcaram lugares específicos onde, futuramente, outros guarani mbya viriam a fundar suas tekoa (aldeias), num tempo em que as políticas públicas de demarcação de terras indígenas não mais permitissem a efetivação do modo de vida "dos antigos", ou seja, o "caminhar sob a luz" (Ladeira, 2007). Com a necessidade de se deterem em determinados lugares, os Mbya buscam atualmente, além de sinais dos antepassados, justificativas legais para a fundação de novas aldeias, como a presença de sambaquis (Cretton, 2010) na aldeia situada na cidade de Niterói (RJ).

Ocupada a partir da "permissão oral" do proprietário do lugar, a aldeia do Mamanguá é a menor em termos populacionais (possui por volta de 15 habitantes) e está localizada em uma propriedade particular, um "sítio do jurua (branco)" como dizem eles, o que significa dizer que a área não foi ainda homologada como Terra Indígena pela Fundação Nacional do Índio (FUNAI). Tal fato, segundo informações colhidas durante o trabalho de campo, constitui-se uma das razões pela qual o atendimento em saúde é feito de uma maneira minimamente inconstante, isto é, sem uma assiduidade regular e também sem a existência de um local apropriado (como uma unidade/ posto de saúde, por exemplo). Vale a pena destacar que esta aldeia foi formada por pessoas que saíram da aldeia de Paraty Mirim, atualizando o movimento empreendido pelos guaranis.

A região conhecida pelos moradores da vila de Paraty Mirim como Morro do índio, tem sido ocupada pelos Guarani Mbya em diferentes momentos, desde a década de 1940. Homologada junto com as TI's de Bracuí e Araponga, na década de 1980, graças a um esforço conjunto dos Guarani e do Centro de Trabalho Indigenista (CTI), a aldeia de Paraty Mirim possui 76 hectares e abriga por volta de 100 guaranis. A Terra Indígena Itaxi (pedra branca, nome em Mbya da aldeia de Paraty Mirim) possui escola e posto de saúde que estão localizados próximos a uma estrada asfaltada que passa por dentro da TI. O posto funciona diariamente com a presença de técnicas de enfermagem e dois agentes indígenas de saúde, moradores da aldeia. A visita do médico ocorre basicamente uma vez na semana.

A Terra Indígena Guyraitapu (nome em Mbya da aldeia de Araponga) possui por volta de 30 habitantes chefiados por um cacique que também é pajé (especialista curador e líder espiritual), possui 295 hectares sendo, portanto, uma das maiores da região. Possui escola e posto de saúde, ambos não funcionam diariamente. Dois filhos do cacique exer- 
cem as funções de professor e agente indígena de saúde. A equipe EMSI atende uma vez por semana na aldeia, salvo em ocasiões climáticas que tornem a sua chegada impossível, já que a estrada que leva à aldeia, além de ser muito íngreme, ainda é de terra batida e muito irregular. Para garantirem sua mobilidade e também o transporte de doentes, os moradores possuem uma caminhonete com tração nas quatro rodas, doada por um filantropo italiano.

\section{Formulando estratégias de trabalho em campo}

Algumas modificações tiveram que vir a cabo, na estratégia metodológica inicial, diante de nossa mudança de planos de pesquisa (ampliação do número de aldeias), e também de acordo com as experiências que vivíamos em campo. A observação participante continuou a ser o principal instrumento de trabalho de nossa equipe, porém notamos a importância de realizarmos entrevistas com questionários semiestruturados (geralmente específicas para cada entrevistado) para termos acesso a certos dados, às vezes, indisponíveis numa conversação cotidiana. Consideramos como semiestruturados os questionários formulados a partir de alguma questão específica que estivéssemos a fim de investigar. Assim, ainda que a entrevista se realizasse, muitas vezes, num tom informal, de conversa, procurávamos seguir, de forma minimamente objetiva, a ordem de perguntas previamente definidas.

Simultaneamente percebemos a dificuldade de seguir questionários preparados com antecedência, de modo que desenvolvemos o hábito de conversar entre nós previamente sobre o assunto a ser tratado em determinada entrevista. Desta forma, utilizávamos, via de regra, nosso pequeno gravador digital, sendo que, eventualmente, um de nós levava um caderno a fim de acompanhar a entrevista com anotações pontuais. Realizamos, assim, entrevistas com lideranças (caciques, pajés e pessoas mais velhas) e outros membros da comunidade, e também com os profissionais da equipe de saúde indígena, tais como: médicos, enfermeiras, técnicas de enfermagem e AIS.

Também é interessante ressaltar que houve certas situações nas quais nos víamos já realizando uma "entrevista", mas sem ter nem gravador nem caderno em mãos. Tal situação ocorria devido à fluidez do ritmo da observação participante no cotidiano dos Guarani, o que nunca aconteceu em relação aos membros da EMSI, com os quais a entrevista era feita de uma maneira mais formalizada. Nas conversas cotidianas 
com os Guarani, procurávamos fazer perguntas importantes para nossa pesquisa e, logo após o término do diálogo, saíamos em busca de nossos cadernos para anotarmos de memória tudo quanto conseguíssemos lembrar. Este modo de proceder mostrou-se bastante eficaz, posto que melhor se adequava ao "tempo" guarani, tal como o experimentamos em nossa vivência nas aldeias.

As viagens a campo aconteceram numa periodicidade média de uma vez por mês, de janeiro a dezembro de 2009, com duração de 3 a 5 dias cada uma. Fazendo parte de um processo público de seleção de Propostas Avaliativas do Subsistema de Saúde Indígena, nosso projeto necessitou passar por algumas instâncias de aprovação, recebendo de todas elas um parecer favorável: $\mathrm{CNPq}$, orgão que foi também o financiador da pesquisa; Comissão Nacional de Ética em Pesquisa (CONEP); e finalmente a FUNAI, que nos forneceu a autorização oficial para entrada nas Terras Índígenas.

\section{Exai ha'e mba'eaxy: saúde e doença na experiência dos mbya guarani}

Existe, na literatura antropológica sobre os Guarani, um amplo consenso sobre as razões cosmológicas que seriam capazes de explicar a vocação migratória deste povo. A busca pela chamada Terra Sem Males (yvy marã e 'ÿ) seria, então, o elemento central desta vocação. A distinção fundamental, portanto, entre a terra imperfeita dos homens e esta terra divina, livre dos males que atingem a primeira, seria, justamente, sua condição de durabilidade. Nhanderekoaxy ("nossa vida dolorosa") é o modo como os Mbya comumente se referem à sua vida terrena, durantes as rezas que acontecem diariamente na opy (casa de reza).

Enquanto a morada de Nhanderu (Deus, literalmente "nosso pai") é eterna; na morada dos homens, as coisas são feitas para não durar, de onde vem a sua condição imperfeita. Deste modo, a cosmovisão Mbya Guarani considera Nhanderu como a fonte inesgotável de saberes (inclusive os poderes de cura doskarai, líderes espírituais) capazes de possibilitar maior durabilidade aos homens na terra imperfeita em que vivem. A antropóloga Elizabeth Pissolato afirma: "Em vez de propor uma solução em tempo futuro de superação da condição mortal através e para além da morte, enfatiza a capacidade de duração que os viventes podem adquirir na sua experiência de vida" (Pissolato, 2007, p.396).

Relacionando esta noção com falas dos Mbya Guarani com os quais convivemos durante o trabalho de campo, percebemos uma associação 
significativa entre os conceitos de saúde e alegria, bem como de doença e desânimo (ou tristeza). Um AIS comentou que ter saúde é se alimentar bem, não estar doente e estar alegre. Uma AIS de outra aldeia, como que para completar o sentido deste comentário, explicou que quando a pessoa está infeliz já é sinal de que está doente. Alegria e tristeza seriam, nesta perspectiva, duas possibilidades ou disposições dos indivíduos mbya em relação a poderes exteriores capazes de agir em seus corpos. Esta dupla possibilidade se relaciona, de forma mais íntima, com o que se pode perceber através de um olhar superficial, com a noção de pessoa/ alma mbya guarani.

Para começarmos a entender esta relação é preciso voltar nossa atenção para o conceito de $n h e^{\prime} e$ comumente traduzido por palavra-alma (ou nome-alma) e que representaria a porção divina do espírito de cada ser humano. Todo Mbya recebe seu nome (nhe'e) Guarani no ritual de nomeação chamado nimongarai, que ocorre anualmente (na maioria das vezes, em sincronia com o período de colheita do milho, isto é, nos meses de dezembro, janeiro e fevereiro) e é promovido pelos pajés (karai ou kunhã karai, para as mulheres) de cada aldeia. Nele, Nhanderu revela ao karai o nome-alma de cada criança, de modo que podemos entendê-la como o fluxo de vida que Nhanderu doa a cada Mbya, pois é ela que mantém erguido o saber divino, através das palavras, como também o corpo humano em sua posição vertical de sustentação ${ }^{1}$. A palavra-alma é a substância do corpo que é ligada ao divino, "é o que anima a pessoa enquanto ela permanece como vivente" (Pissolato, 2007, p.254). Desta forma, se a conversa e a fala tranquila são sinais de boa saúde, a quietude, a preguiça e a falta de ânimo para os afazeres diários são sinais claros de que algum mal está acometendo a pessoa.

Fortalecer-se espiritualmente (mbaraete) seria, portanto, renovar diariamente esta conexão que cada indivíduo mantém com o divino, livrando-se da possibilidade de que potências maléficas ajam sobre os corpos. Contudo, se a nhe'e (alma-palavra) abre os horizontes para a alegria e o ânimo (vy'a), outra porção da alma, o teteregua (literalmente, “do corpo") seria responsável pelos estados de preguiça, desânimo e tristeza. Como explicou um morador da aldeia de Paraty Mirim, quando se dança na opy é esta porção da alma, o teteregua, que se pretende "expulsar" das pessoas.

Assim, em oposição ao princípio divino da alma, a porção telúrica se fortalece quando a pessoa se identifica com os prazeres mundanos e com o modo imperfeito de viver (tekoaxy). Seus sintomas mais extremos 
são: tristeza, desânimo, raiva, cólera, enfim, os sentimentos antissociais que tanto se afastam do modo de ser (teko) guarani expresso pela boa convivência e pela fala tranquila. A identificação com as imperfeições terrenas implica uma relação distanciada para com os ritos e simbolismos do universo sagrado, o que expõe o indivíduo às fraquezas da condição imperfeita deste mundo, o que justifica a presença de enfermidades:

Por este motivo, desde cedo é ensinado ao jovem Mbya a necessidade de se dominar o pochy, o sentimento de cólera, através do desenvolvimento de suas qualidades espirituais, em detrimento das suas imperfeições mundanas. O pochy é a raiz de todo mal para os Guarani e se relaciona com as paixões terrenas, causas principais das doenças de etiologia espiritual. (Pellon, 2008, p. 109).

O desenvolvimento de um modo de vida imperfeito, portanto, condiciona um estado patológico, mais frágil e exposto à tristeza, confusão, ódio, inveja e ambição, males que acometem a alma e colocam o ser humano na posição horizontal. As duas porções da alma seriam representações, portanto, de duas orientações diversas para o agir humano: uma voltada para a espiritualidade, associada à uma vida tranquila e saudável; e outra voltada para a materialidade da vida terrena, associada à raiva e, em última instância, às enfermidades e doenças que acometem o indivíduo.

Neste sentido, podemos entender o processo de adoecimento de um indivíduo guarani mbya tanto pelo enfraquecimento de seu espírito $\left(n h e^{\prime} e\right)$ como pela abertura à agência de potências causadoras de dor, como espectros dos mortos (angue) e espíritos "donos" de lugares (ija kuéry), o que acontece pela via da porção telúrica da alma humana (o teteregua). Certa vez, quando perguntamos a uma pajé sobre as causas das doenças que são tratadas na opy (casa de reza), ela então nos respondeu:

As pedras (que os pajés retiram do corpo do doente) são de nossos parentes mortos... A pessoa da noite que jogou assim a pedra no corpo da gente, por isso que tem pedra no corpo.

Tais pedras e demais sintomas da chamada doença espiritual também podem resultar da agência humana, através dos feitiços.

Podemos entender então o porquê da regularidade diária com que os mbya se dedicam ao ritual na opy, pois é ali, principalmente, que está aberta para a comunidade a chance de se porem sob os cuidados do pajé, de modo que quando há alguém doente é para lá que é primeiramente levado. O exame inicial do pajé é que vai definir se a pessoa deve ou não procurar o posto de saúde da aldeia e o médico jurua. 


\section{A casa de reza, o trabalho espiritual e Nhanderu como meio de efetuar a cura}

Os pajés são os sábios e especialistas curadores que, de uma forma geral, possuem a capacidade de transitar entre as esferas terrena e espiritual para tomar conhecimento da origem da enfermidade e conseguir tratá-la. Como afirma Pissolato, os pajés possuem um conhecimento especializado para "ver a doença" ou "saber o que acontece". Segundo a autora,

Xamãs mbya são [...] especialistas na prevenção e cura de males, [...]. Não se cura apenas o que já se instalou como doença, mas o que pode ainda vir a afligir a pessoa por meios diversos. A cura-prevenção como atividade especializada envolve não apenas o uso de conhecimentos do que se descreve normalmente como a medicina mbya, mas a prática da reza [...] fundamentalmente por sua função terapêutica e a evitação de aflições pela antevisão de possíveis acontecimentos. (Pissolato, 2007, p.342).

A maioria das sessões de cura ocorre nas cerimônias na opy (casa de reza), ao cair da noite, como pudemos inúmeras vezes observar e também participar durante o trabalho de campo. Através do uso ritual do cachimbo (petyngua) pelo qual se fuma apenas tabaco ${ }^{2}$ puro, o Karai percorre as partes geralmente invisíveis do mundo, ouve as palavras sagradas de Nhanderu e retorna com a cura ou com um tratamento para o doente. Nas falas proferidas dentro da opy em que os sábios (e outras pessoas que se disponham a levantar a voz) se dirigem aos deuses, pedese comumente por encorajamento (mbopy'aguaxu) e fortalecimento espiritual (mbaraete).

Realizar ou promover um ritual na opy exige um investimento por parte do pajé, em operações curativas bem como no consumo de grande quantidade de tabaco. De uma forma geral, a doença é extraída do corpo da pessoa na forma de um pequeno objeto (conchas, pedras, estacas de madeira, chumaços de cabelo, etc) que é então apresentado à pessoa e a quem mais queira ver. Candinho, pajé centenário de Paraty Mirim que na época de nosso trabalho de campo já havia falecido, afirmou para Elizabeth Pissolato (2007, p.345) que "por si mesmo ninguém faz [...]. Se Nhanderu não mostra, não quer...", chamando a atenção para a necessidade de se escutar Nhanderu como único meio de efetuar a cura.

Observamos também que as curas, isto é, a expulsão de doenças do corpo das pessoas, também ocorre durante a execução das rezas (mborai, "música" ou "canto"). Quando o rezador (oporai va'e, o qual pode ou não coincidir com a figura do karai) se põe a executar seu canto, 
os outros participantes do ritual começam a acompanhá-lo num coro de vozes e também com uma dança, na qual se pula com os dois pés juntos, em círculo e no sentido anti-horário. É durante estas danças que os indivíduos podem receber a cura diretamente de Nhanderu, momento em que caem desmaiados e são levados até o pajé, que "benze" (venje) a pessoa com a fumaça de seu cachimbo. Assim, percebemos que a habilidade para a cura e para a prevenção de doenças, antes de ser definida como exclusividade dos especialistas (pajés), se distribui de maneira variada entre os Mbya de um modo geral.

A reza, o canto, a dança, o consumo do tabaco no petyngua são, desta forma, meios de conexão com o divino, além de representarem formas de proteção fornecidas pelos deuses e acessíveis a praticamente todo Mbya. Assim, para o indivíduo se fazer durar nesta terra em que tudo é feito para se acabar, é preciso estar atento e saber escutar o conhecimento divino, cuja fonte inesgotável é Nhanderu. Manter-se em contato com esta fonte através da participação diária no ritual da opy e no uso do petyngua seria o foco do teko (vida, costume, modo de ser) Guarani e aspecto essencial de sua religiosidade.

\section{A coexistência de saberes: respeitando as diferenças}

Tal como exposto acima, vimos que basicamente existem duas formas principais de tratamento das pessoas doentes. A primeira é o pajé, sábio/curador que cura através da reza/canto e do uso do tabaco fumado no petyngua (cachimbo). Se alguma pessoa da aldeia fica doente, é levada primeiramente para o pajé, o qual indica o tratamento: ou ele mesmo conseguirá curar, ou então a pessoa deve ser levada para o médico jurua. Aqui encontramos a segunda forma de terapêutica observada, qual seja, a da equipe de saúde da FUNASA que atende as aldeias. Embora possa parecer que a equipe possui um papel de coadjuvante em relação aos saberes tradicionais, sua importância reside justamente na possibilidade de tratar os males que o pajé, especializado em curas ditas espirituais, não é capaz de "tirar" do corpo da pessoa.

Para além do poder de cura do pajé, há uma sabedoria sobre a ação curativa das plantas do mato (moã ka'aguy, "remédios do mato"), que é mais ou menos generalizada, principalmente entre as pessoas mais velhas das aldeias. De uma forma geral, quem conhece os moã ka'aguy procura ensinar para seus filhos e netos através mesmo da aplicação: para picada de cobra, para dor de cabeça, dor de barriga, febre, gripe 
etc. O pajé, em sua posição de especialista, costuma se diferenciar deste tipo de terapêutica, afirmando que só usa petyngua mesmo para curar as pessoas.

Considerando as formas guarani e jurua (não-índios) de tratar as doenças e sua relação, observamos que há uma nítida separação entre ambas: se, em algum lugar elas se encontram, é justamente no respeito que uma tem pela outra. Quando perguntávamos sobre atenção diferenciada e explicávamos que é o atendimento respeitando a cultura dos povos indígenas, os guarani respondiam, na maioria das vezes: "Ah, isso a gente não tem do que reclamar não, a FUNASA respeita muito".

Sugerimos que aqui respeito significa que a FUNASA não procura impôr o seu modo e o seu ponto de vista sobre a doença e os modos de tratá-la, mas busca um diálogo com os Guarani e sabe escutar o que eles têm a dizer, principalmente nas reuniões do Conselho Indígena de Saúde.

Esta questão do respeito tornou-se fundamental em nosso trabalho na medida em que percebemos sua centralidade na investigação das formas pelas quais os saberes se articulam. Se tínhamos, portanto, como objetivo inicial, observar a implantação do Subsistema de Saúde Indígena tendo por foco a articulação entre o saber indígena e o saber biomédico, tal articulação tomou forma para nós, inicialmente, no respeito que permeia a relação entre as duas práticas.

Certa vez perguntamos a uma técnica de enfermagem se ela conhecia remédios "naturais" como chás de erva e coisas deste tipo, e se tinha interesse em receitá-los para os Guarani. Sua resposta imediata foi que ela deixava isso pra eles. Num outro momento, quando conversávamos sobre o medo de agulhas e de tomar injeções, perguntamos a um morador de Paraty Mirim se ele preferia tomar injeções e remédios do jurua (branco) ou chá. Como ele respondesse que preferia o chá, percebemos como o dito "respeito" pela cultura pode delimitar pontos de vista e campos de ação, dificultando uma articulação efetiva.

\section{Subsistema de Saúde Indígena e atenção diferenciada}

A partir da Constituição Brasileira de 1988, a qual reconhece o caráter pluricultural do Estado, e da aprovação da Lei Orgânica da Saúde (Lei n. 8080/90), que reconhece o direito do acesso dos índios ao Sistema Único de Saúde (SUS) através da universalização da saúde, começa-se a pensar em um subsistema de atenção básica nas áreas indígenas (Langdon, 2004, p.37). 
Ao tratar dos direitos dos Povos Indígenas, a Constituição Federal, no Artigo 231, ressalta: "São reconhecidos aos índios sua organização social, costumes, línguas, crenças e tradições, e os direitos originários sobre as terras que tradicionalmente ocupam, competindo à União demarcá-las, proteger e fazer respeitar todos os seus bens." (Brasil, 1988, Art. 231).

Mas, só a partir de 1999, passa-se a preconizar um atendimento sistematizado e contínuo para as populações indígenas, com o Decreto n. 3.156 , de 28 de agosto, que esclarece como será a prestação de assistência à saúde dos povos indígenas inserida no Sistema Único de Saúde e institui os Distritos Sanitários Especiais Indígenas (DSEIs), que são responsáveis pela organização da atenção básica nas aldeias, além de reconhecer o valor e a complementariedade das práticas da medicina indígena, segundo as peculiaridades de cada comunidade. A Lei n. 9.836/99 de 31 de agosto, conhecida como "Lei Arouca" institui o Subsistema de Atenção à Saúde Indígena e discorre sobre a promoção, proteção e recuperação da saúde e sobre como será o funcionamento e a organização deste subsistema. Além da Portaria n. 1.163/GM, de 14 de setembro, a qual determina que a FUNASA/MS será o órgão responsável pela saúde indígena, associada diretamente à Secretaria de Assistência à Saúde, de acordo com a Política de Atenção à Saúde dos Povos Indígenas.

Ao analisar o modelo de atenção aos povos indígenas, Diehl (2001, p. 440) lembra que: "com a implantação dos DSEI's, pretende-se alcançar mudanças significativas nas políticas de saúde indígena e na gestão de projetos direcionados ao atendimento integral dessas populações, procurando efetivar um modelo diferenciado de atenção com base na especificidade de cada um dos diversos grupos".

Dentro desta política, o Subsistema de Saúde Indígena está organizado em 34 DSEIs em articulação com o Sistema Único de Saúde. Esse subsistema deve atender aos seguintes critérios, segundo a FUNASA (2002): respeitar o conhecimento acerca do processo saúde, doença e cura das populações e todos os aspectos que interferem nessa tríade; sua construção deve ser coletiva e se originar de um planejamento participativo; deve-se contar com o controle social formal em todas as instâncias de decisão.

De acordo com a FUNASA (2002, p. 13), o DSEI desenvolve ações de atenção à saúde através da reorganização da rede de serviços de saúde (que se localizam dentro de seu território de abrangência). Essa rede deve ser integrada e estabelecer o sistema de referência e contrarreferência com oSUS para situações de maior complexidade. 
A Atenção à Saúde Indígena realizada no estado do Rio de Janeiro faz parte do DSEI Litoral Sul; é gerenciada pela Coordenação de Assuntos Indígenas da FUNASA que se localiza na cidade do Rio de Janeiro e administrada pelo Polo Base que se encontra em Angra dos Reis e tem como função administrar a assistência, além de fazer a capacitação e supervisão dos AIS. Já nas terras indígenas propriamente ditas, a atenção à saúde fica por conta das EMSIs, que são compostas por médico, enfermeiro, técnico de enfermagem, odontólogo, auxiliar de consultório e pelos AISs. Segundo Langdon et al. (2006, p.2637), o agente indígena de saúde tem "o papel definido na atenção básica de saúde como mediador entre os saberes e práticas de atenção à saúde tradicionais e biomédicos".

Todo o processo de construção e estruturação do subsistema de saúde indígena deve contar com a participação de representantes indígenas, através de suas lideranças e/ou organizações, o que se denomina como controle social, que está envolvido em todas as etapas, desde a formulação de políticas até a avaliação da prestação da assistência à saúde. “Os Conselhos Locais de Saúde serão constituídos pelos representantes das comunidades indígenas da área de abrangência dos Polos-Base, incluindo lideranças tradicionais, professores indígenas, AIS, especialistas tradicionais, parteiras e outros" (FUNASA, 2002, p.21). Esses Conselhos, que têm ocorrido no Polo Base de Angra dos Reis, devem identificar as necessidades e agravos de saúde que acometem as populações das aldeias atendidas.

De acordo com o mesmo autor, os Conselhos Distritais de Saúde têm caráter deliberativo e são constituídos por composição paritária: metade dos membros dos Conselhos são usuários e a outra metade são de organizações governamentais, prestadores de serviços e trabalhadores da área da saúde do distrito. As reuniões do Conselho ocorrem na sede do DSEI Litoral Sul, em Curitiba (PR).

O Controle Social em nível nacional é desenvolvido pela Comissão Intersetorial de Saúde do Índio (CISI), que está vinculada ao Conselho Nacional de Saúde (CNS). A CISI deve auxiliar o CNS na formulação e no acompanhamento de políticas públicas de saúde indígena (Langdon, 2004, p. 38).

A partir da Constituição de 1988, e da formação do Subsistema de Saúde Indígena, com o Decreto n. 3. 156 e da Lei n. 9.836, ambos de 1999, surge a questão da atenção diferenciada, que é interpretada como a necessidade de respeito e de valorização das práticas de saúde tradicio- 
nais e adaptação das ações de saúde oferecidas pelo governo às peculiaridades socioculturais, epidemiológicas e demográficas das diversas etnias indígenas (Silveira, 2004, p. 111).

O princípio que permeia todas as diretrizes da PNASPI é o respeito às concepções, valores e práticas relativos ao processo saúde-doença próprios de cada sociedade indígena e a seus diversos especialistas. A articulação com esses saberes e práticas deve ser estimulada para a obtenção da melhoria do estado de saúde dos povos indígenas (FUNASA, 2002, p.17-18).

De acordo com Menéndez 33 (2003 apud Langdon, 2004, p.42), atenção diferenciada não é a utilização de práticas tradicionais da medicina indígena pelos serviços de saúde e sim uma articulação entre o saber biomédico e as práticas de autocuidado existentes nas comunidades indígenas.

Para falar sobre atenção diferenciada e articulação entre saberes, devemos nos lembrar que os povos indígenas, antes de serem atendidos pela Política de Saúde do Governo, já possuíam a sua própria cultura e/ ou conhecimento em saúde, métodos tradicionais de cuidado e interpretação do processo saúde, doença e cura. Assim, é preciso reconhecer que estes saberes devem ser respeitados e integrados nas ações de saúde oferecidas a eles, numa articulação entre ambas as concepções de práticas em saúde, onde um complemente o outro, sem se sobrepor a ele. Esta é uma das maiores dificuldades para se realizar a atenção diferenciada: conceber que não é um conhecimento/saber que está certo ou é verdadeiro e o outro errado ou é menos verdadeiro, e sim que ambos existem e devem ser utilizados na melhoria das condições de saúde da população indígena.

\section{As dificuldades no atendimento}

O respeito existente na relação entre os modos indígena e biomédico de cuidado não implica sua articulação efetiva, inclusive porque os coordenadores da FUNASA encontram dificuldades estratégicas que exigem bastante da sua habilidade de gerenciação. Com a enorme demanda com que precisa lidar, a FUNASA-RJ sofre com um esquema de distribuição de recursos que não leva em conta as especificidades locais. Em Brasília, explicou-nos a coordenadora da saúde indígena do Rio de Janeiro, os cálculos para envio de recursos são feitos tendo por base a quantidade de indivíduos, isto é, o montante é calculado a partir de uma medida per 
capita. Tal esquema pode funcionar bem para uma aldeia de 1000 índios, por exemplo, porém sofre deficiências caso esses mesmos 1000 indivíduos encontrem-se espalhados por cinco aldeias ou mais. Os gastos em gasolina para o deslocamento e também o tempo gasto não estão sendo levados em conta.

O caso da aldeia do Mamanguá é bastante ilustrativo desta situação, pois o acesso se faz somente pela água, e por isso depende de gasolina para a canoa a motor, além de condições climáticas minimamente navegáveis. Por conta dessas dependências, muitas vezes a equipe fica impossibilitada de visitar a aldeia. Se há alguma emergência, os moradores precisam levar a pessoa de canoa até a outra margem do Saco do Mamanguá e dali fazer uma trilha até Paraty Mirim, onde há posto de saúde. O difícil acesso é uma importante questão para a saúde dos moradores desta aldeia.

Outra questão que apareceu nas falas dos sujeitos da pesquisa refere-se à rotatividade dos membros da EMSI, seja por razões internas da FUNASA, seja por reivindicações dos próprios Guarani. É relevante, em relação a esta questão, que a qualificação de uma pessoa para trabalhar nas aldeias guarani mbya tem como item essencial a sua familiarização com os habitantes, isto é, o estabelecimento de relações e vínculos com os indivíduos guarani, estimulando sua confiança em relação ao trabalho que está sendo realizado pela equipe de saúde. Langdon (et al 2006, p. 2640) neste sentido destaca que "a alta rotatividade dos profissionais de saúde nas EMSI não é característica somente desse DSEI, mas uma realidade nos outros 33 DSEI's espalhados pelo país".

A rotatividade de profissionais acaba por desfazer os vínculos e interromper os processos iniciados, comprometendo a assistência prestada aos indígenas. Cada novo profissional que se insere na EMSI precisa reiniciar ou refazer a relação de confiança com os Guarani e inserir-se na produção do campo das ciências sociais, apropriando-se da produção socializada sobre este grupo indígena. Além disso, como explicounos um médico que trabalhou muitos anos na equipe, minimamente $o$ integrante da EMSI deve dedicar-se à leitura antropológica acerca do grupo indígena com o qual está trabalhando. 


\section{Reflexões acerca do cotidiano na atenção à saúde indígena}

A partir de nossas observações em campo, surgiu uma questão fundamental: qual seria o momento de articulação local ou o movimento de "sentar junto", coletivamente, para resolver as questões que emanam da atenção à saúde desta população que apresenta tantas especificidades? Segundo um dos médicos entrevistados, essa "conversa" que deveria existir, pelo menos na reunião de equipe, não acontece. Os AIS não participavam das reuniões e eles relataram sentir falta disso, até para se perceberem mais integrados à EMSI. Ao tentar explicar este fato, uma das coordenadoras diz que isso não ocorre porque há especificidades em cada aldeia e um AIS não necessitaria saber da problemática de uma comunidade que não a sua. E exemplifica dizendo que um AIS não precisa saber que um indígena que não é de sua aldeia seja HIV positivo.

Participando de um Conselho Local, nós estranhamos o fato de os Guarani se reunirem para discutir e só ao final do dia chamarem o pessoal da FUNASA para fazer suas colocações. Esperávamos que fosse um espaço de construção coletiva de soluções e não apenas de pontuações sobre problemas que teriam que ser solucionados, mas, na visão de um AIS, o conselho é o espaço de colocação, no qual as questões podem ser compartilhadas. Em resposta ao nosso questionamento sobre se a FUNASA atende respeitando a cultura (isto é, se ela atende com base na diretriz da atenção diferenciada), o mesmo AIS esclarece:

Pra isso a gente tem o nosso conselho... a gente vem falando isso pra eles, então eles respeitam a cultura, o pajé, as parteiras, então eu acho que isso tudo acontece no nosso trabalho com a FUNASA.

Observamos também que não há um consenso entre os sujeitos da pesquisa, em relação ao conceito de atenção diferenciada. Para os Guarani, o atendimento, no que tange ao "respeito à cultura", tem sido realizado satisfatoriamente, enquanto para alguns profissionais da equipe o conceito de "diferenciada" acaba por atuar como fator limitante, tal como acontece quando se tem que escolher entre o respeito à cultura e ética profissional. Um fato ilustrativo é o seguinte caso relatado por uma das coordenadoras de assuntos indígenas: os pais não queriam deixar fazer uma traqueostomia numa criança, e o Minisitério Público teve que ser acionado para que a criança não morresse e o tratamento proposto pela FUNASA pudesse ser realizado.

Outra observação feita pela mesma coordenadora é a de que a atenção diferenciada não ocorre o tempo todo, ela é realizada em momentos 
específicos, como por exemplo, quando a FUNASA levou em um dos seus carros um garoto que a família achava que tinha uma doença espiritual para tratamento com pajés em São Paulo e Paraná. Em referência ao evento citado acima, ela diz:

Então a gente procura ajudar... fazer o tratamento complementar, pra gente é complementar, mas para eles é principal, e o nosso é que é complementar, mas enfim a gente faz a contribuição necessária.

Já para uma AIS de Paraty Mirim, a FUNASA tem atendido à comunidade com respeito à sua cultura, como aparece na fala seguinte:

A gente tem alguma gestante na aldeia e o pré-natal é mensalmente, a gente vê, se a mãe não tem nenhum risco, aí eles podem ganhar na aldeia, não tem nada a ver, eles não contrariam isso e eu acho que isso é muito importante.

Os integrantes da equipe de saúde sabem e respeitam o tratamento inicial do pajé em relação às chamadas doenças espirituais na casa de reza (opy), um modo de cuidar cuja explicação é referenciada na cosmologia guarani mbya. Caso não seja esta a natureza da doença, o pajé encaminha a pessoa para a equipe de saúde, como já explicamos acima. Considerando, portanto, essas duas formas de tratamento, observamos que há um certo nível de negociação entre elas, porém reparamos que uma efetiva articulação não acontece, pois raramente atuam juntos. Segundo a FUNASA (2002, p.18), "A articulação com esses saberes e práticas deve ser estimulada para a obtenção da melhoria do estado de saúde" Reafirmamos, portanto, que há certo distanciamento entre os modos indígenas de cuidado e o tratamento da equipe multidisciplinar, cada qual possuindo seu campo de ação.

Sublinhamos também a questão da falta de formação qualificada ou específica para os profissionais da saúde que vão trabalhar nas aldeias. A formação na área da saúde não traz para os graduandos questões que os aproximem das especificidades culturais dos diferentes grupos étnicos (indígenas, quilombolas etc.) existentes no Brasil. Pelo contrário, as reformas curriculares que passaram a vigorar no campo da saúde, a partir de 2001, condensaram conteúdos fundamentais para se trabalhar com culturas diversas. Segundo uma das entrevistadas que já trabalhou pela FUNASA, no Amazonas, nem mesmo naquela região em que a população indígena é tão expressiva, havia um grande interesse dos alunos e dos cursos em relação ao tema. Desse modo, a formação e a capacitação dos profissionais que atuam nas equipes multidisciplinares de saúde indígena deixam lacunas geradoras de insegurança durante o desenvolvimento de suas práticas. 
A fim de tentar amenizar este problema, os coordenadores da saúde indígena organizam um curso introdutório de antropologia para os membros da equipe multidisciplinar, focado na etnia guarani. Admitese que o curso é capaz de dar certa orientação à prática destes profissionais, porém, observamos que é mesmo no fazer cotidiano e na relação com os Guarani Mbya que se aprende a "fazer" a atenção diferenciada. Apesar disto, alguns destes profissionais encontram muita dificuldade em lidar com uma cultura tão diferenciada, mesmo após o convívio diário, razão pela qual mantém uma relação um pouco desgastada e distante em relação aos moradores das aldeias nas quais trabalham.

Todos estes fatores (e também levando em conta que a maioria dos profissionais com os quais conversamos eram contratados) contribuem para uma alta rotatividade de profissionais, o que prejudica a construção de uma relação mais íntima e de confiança entre a equipe e os Guarani. Corroborando com os achados, Langdon (et al. 2006, p.2640) ainda destaca: "A alta rotatividade dos membros das equipes, frente à ausência de capacitação adequada, seja esta de forma contínua, como recomendado pela PNASPI, ou de cursos pontuais, resulta na falta de preparação por parte dos profissionais para o trabalho em contextos étnicos específicos."

Por fim, outro ponto que nos chamou a atenção foi a falta de uma definição mais clara e específica, pelos Guarani, em relação ao papel da FUNASA. Sugerimos que um dos fatores implicados nesta indefinição seja a abrangência da atual concepção de "saúde" que deve englobar, além de assistência à saúde, fatores que influenciam na saúde dos povos indígenas, tais como: meio ambiente, saneamento básico, alimentação, direito a terras, educação sanitária, habitação, paz, educação, justiça social e renda, segundo a I Conferência Internacional sobre Promoção da Saúde e a Política de Atenção à Saúde dos Povos Indígenas.

Como no discurso dos indígenas, a FUNASA é responsável pela "saúde", de uma forma geral, e acaba se tornando "encarregada" de todos estes fatores que influenciam uma vida saudável. Como fator contribuinte para esta indefinição, tem-se também a relação tutelar que o Estado brasileiro estabeleceu historicamente com os povos indígenas, resultando em uma sobrecarga de funções atribuídas à FUNASA, como observamos em nosso trabalho de campo. Como exemplo da falta de delimitação do papel da FUNASA, por parte dos indígenas, um dos entrevistados nos relatou que uma Guarani havia solicitado do órgão que lhe fornecesse creme hidratante. 


\section{Considerações finais}

Com base nas observações realizadas, reafirmamos que a atenção diferenciada às diferentes etnias indígenas do Brasil se efetivará ou se tornará realidade quando forem colocadas realmente em prática as ações como a participação de representantes das comunidades na formulação de políticas e na execução das ações e serviços; o preparo/ formação acadêmica das equipes de saúde para que compreendam e valorizem a cultura indígena e o desenvolvimento de estratégias de atenção primária em âmbito local que respeitem as especificidades etnoculturais. Essas ações representam o ponto de partida para a discussão da integração da assistência dos indígenas às redes de serviços do Sistema Único de Saúde, sem que sofram preconceito e também representa o caminho para melhoria da atenção em saúde desta população.

Ficou evidenciado pelo estudo que a saúde dos povos indígenas é expressão direta da política indigenista desenvolvida no país. Os dados, ainda que preliminares, sugerem que para que se possa atingir a meta de realizar uma atenção diferenciada, algumas estratégias deverão ser consideradas ou reconsideradas, como a manutenção complementar das práticas tradicionais de cura, o treinamento especial dos profissionais de saúde não-índios integrantes da EMSI, com base em conhecimentos etnológicos e o estabelecimento de formas diferenciadas de articulação com as diferentes instâncias de gestão do SUS.

Destacamos também que a valorização do serviço e do saber e o papel de articulação entre comunidade e a EMSI desenvolvido pelos agentes indígenas de saúde são elementos importantes para se atingir a questão da atenção diferenciada e se efetivar o controle social, além de contribuir para a maior autonomia, a continuidade das ações de saúde desenvolvidas, bem como para a redução de custos. Ficou evidente também que não há um tempo certo ou ideal para a articulação entre os saberes biomédico e indígena acontecer. Essa articulação deve ter lugar sempre que oportuna e necessária.

Por fim, a partir das questões levantadas com base neste estudo e considerando a atenção diferenciada como diretriz que permeia a atenção aos povos indígenas, sugerimos que o planejamento das ações em saúde considere todas as especificidades locais e culturais dos Mbya Guarani, bem como os distintos contextos de suas aldeias. 


\section{Notas}

${ }^{1}$ Segundo Pissolato (2007), as crianças só recebem seus nomes-alma quando dão mostras de que querem "ficar", isto é, querem sobreviver e existir nesta terra, como pessoas. Como a fala, o dizer é o que ergue a alma que Nhanderu envia, as crianças são desde cedo estimuladas a falar e a andar, que são entendidos como sinais de seu desejo de "ficar" e viver junto de seus parentes.

${ }^{2} \mathrm{O}$ tabaco (fumado no petyngua) é tido pelos Mbya como um veículo de comunicação direta com Nhanderu e é fumado cotidianamente por homens e mulheres.

${ }^{3}$ Menéndez, E. Modelos de atención de los padecimientos: de exclusiones teórias y articulaciones práticas. Ciência \& Saúde Coletiva, v.8, n.1, p.185-208, 2003.

\section{Referências}

BONAMIGO, Zélia. Comunidade Mbya-Guarani: economia e relações com a sociedade atrevida. Tellus, Campo Grande, n. 14, p. 145-170, abr. 2008. Disponível em: <http:/ / www.neppi.org/projetos/tellus_detalhes.php?id=267>. Acesso em: 2 abr. 2010.

BRASIL, Constituição da República Federativa do Brasil, de 5 de outubro de 1988. Disponível em: <http://www.planalto.gov.br/ccivil_03/constituicao/ constitui\%C3\%A7ao.htm>. Acesso em: 4 abr. 2010.

CRETTON, Vicente. Mbya reko e elementos urbanos: encontros dos Guarani Mbya com a cidade em contextos distintos de ocupação no Estado do Rio de Janeiro. In: Intratextos, Rio de Janeiro, número especial 1, p.85-102, 2010.

CICCARONE, Celeste. Drama e sensibilidade: migração, xamanismo e mulheres mbyá. In: Revista de Indias, v. LXIV, n. 230, p. 81-96, 2004.

DIEHL, Eliana Elizabeth. Agravos na saúde Kaingáng (Terra Indígena Xapecó, Santa Catarina) e a estrutura dos serviços de atenção biomédica. In: Cadernos de Saúde Pública, Rio de Janeiro, v.17, n.2, p. 439-445, mar./abr. 2001.

FUNDAÇÃO NACIONAL DE SAÚDE. Política Nacional de Atenção à Saúde dos Povos Indígenas. 2. ed. Brasília: Ministério da Saúde. Fundação Nacional de Saúde, 2002. Disponível em: <http://www.funasa.gov.br/internet/arquivos/biblioteca/ sauInd_politica.pdf>. Acesso em: 3 abr. 2010.

LADEIRA, Maria Inês. Espaço geográfico Guarani Mbya. Significado, constituição e uso. Maringá, PR: Eduem; São Paulo: Edusp, 2008.

2007.

. O caminhar sob a luz: território mbya à beira do oceano. São Paulo: UNESP,

LANGDON, Esther Jean. Uma avaliação crítica da atenção diferenciada e a colaboração entre a antropologia e profissionais de saúde. In: LANGDON, Esther Jean; GARNELO, Luiza (Orgs.). Saúde dos povos indígenas: reflexões sobre antropologia participativa. Rio de Janeiro: Contra Capa, 2004.

LANGDON, Esther; DIEHL, Eliana; WIIK, Flavio; DIAS-SCOPEL, Raquel. A participação dos agentes indígenas de saúde nos serviços de atenção à saúde: a experiên- 
cia em Santa Catarina, Brasil. In: Cadernos de Saúde Pública, Rio de Janeiro, v. 22, n.12, p.2637-2646, dez. 2006.

PELLON, Luiz Henrique Chad. Tensões interculturais e os impactos no processo saúdedoença na população Guarani Mbyá do município de Aracruz, Espírito Santo. 2008. Dissertação (Mestrado em Enfermagem) - CCBS/UNIRIO, Rio de Janeiro, 2008.

PISSOLATO, Elizabeth. A duração da pessoa: mobilidade, parentesco e xamanismo mbya (guarani). São Paulo: UNESP, 2007.

SILVEIRA, Nádia Heusi. O conceito de atenção diferenciada e sua aplicação entre os Yanomami. In: LANGDON, Esther Jean; GARNELO, Luiza (Orgs.). Saúde dos povos indígenas: reflexões sobre antropologia participativa. Rio de Janeiro: Contra Capa, 2004.

Recebido em 8 de abril de 2010

Aprovado para publicação em 7 de julho de 2010 
